\title{
Factors associated with changes of the frailty status after age 70: findings in
}

\section{the MAPT study}

Authors: Marie HERR ${ }^{1}$, Matteo CESARI ${ }^{1,2}$, Benjamin LANDRE $^{3}$, Joël ANKRI ${ }^{3}$, Bruno $\operatorname{VELLAS}^{1}$, Sandrine ANDRIEU ${ }^{1,4}$, and the MAPT/DSA study group*

${ }^{1}$ LEASP, UMR 1027, INSERM, UPS, Université de Toulouse, France

${ }^{2}$ Geriatric Unit, Fondazione IRCCS Ca' Granda-Ospedale Maggiore Policlinico, Università di Milano, Milan, Italy

${ }^{3}$ INSERM, U1168, VIMA: Aging and chronic diseases. Epidemiological and public health approaches, Villejuif, F-94807, France; Univ Versailles St-Quentin-en-Yvelines, UMR-S 1168, F-78180, Montigny le Bretonneux, France

${ }^{4}$ Department of public health, CHU de Toulouse, France

Short title: Factors associated with frailty transitions in the MAPT study

Corresponding author: Marie Herr, UMR 1027, Faculté de médecine, 37 allées Jules

Guesde, 31000 Toulouse, Tél: 33 (0)5 611459 63, Fax: 33 (0)5 622642 40,

marie.herr@inserm.fr

Keywords: depression, frail elderly, gender, transitions, predictors, polypharmacy

Word count: 2326

No. of references: 40

No. of tables: 3

No. of figures: 1

No. of appendices: 2 


\section{Abstract}

Purpose: Frailty has become a major issue in the prevention of functional decline and disability in aged populations. Using repeated measurements of frailty over 3 years, this work aimed to describe transitions between frailty states and associated factors. Methods: This study used the data from the Multidomain Alzheimer Prevention Trial (MAPT) and included the 842 participants aged 70 and over who did not receive the multidomain intervention. Frailty was assessed using the phenotype proposed by Fried et al. at baseline and at 6, 12, 24, and 36 months. Factors influencing the transitions across frailty states were examined using multistate modelling. Results: The study population included 548 women and 294 men, mean age 75.4 +/- 4.5 years. At baseline, 430 (53\%) participants were non-frail, 349 (43\%) pre-frail, and 28 (4\%) frail. A total of 2271 pairs of consecutive measurements of frailty status were available over the 3 years of follow-up, with no change in frailty status in 1548 of them (68\%), a worsening of frailty status in 426 of them (19\%), and an improvement in frailty status in the remaining 297 (13\%). Polypharmacy (i.e. $\geq 6$ drugs) and probable depression were associated with incident pre-frailty. Female gender was systematically associated with a lower probability of recovering from pre-frailty and frailty. Older age, overweight, comorbidity, and abnormal CRP also reduced the probability of recovery from frailty or pre-frailty. Conclusions: This study sheds light on factors that should be further investigated in future research to help the prevention and management of frailty. 


\section{Introduction}

Frailty is defined as an ageing-related state, resulting from a decrease in physiological reserves across multiple systems, increasing vulnerability to stressors. ${ }^{1}$ From this theoretical basis, multiple operational definitions of frailty have emerged..$^{2}$ The most commonly used is the frailty phenotype, which is based on a set of five criteria exploring physical strength, physical activity, nutrition, mobility and energy. ${ }^{3}$ Frailty has been shown to affect between 11 and $14 \%$ of people aged 65 years and over and to be a predictor of adverse health outcomes, such as falls, institutionalization, and mortality. ${ }^{4,5}$

As such, frailty has become a major issue in the prevention of functional decline and disability in aged populations. ${ }^{6,7}$ The concept of frailty is now incorporated in public health policies and primary care physicians are encouraged to screen their patients for frailty and to refer them, where necessary, to day hospitals for a full frailty assessment, enabling the provision of personalized interventions to delay health and functional decline. A wide range of interventions are available, including improved management of chronic conditions, physical activity, and nutritional skills. ${ }^{8,9}$

Much research has focused on the dynamic of frailty in longitudinal settings in order to understand the multiple causes of and risk factors for pre-frailty and frailty. Valuable studies in the field ${ }^{10-20}$ have contributed to the description of frailty transitions. However, large intervals between measurements of the frailty phenotype (from 18 months to more than 4 years depending on the study) fail to take into account any change in frailty status that occurred within shorter intervals and may result in transitions being related to risk factors that may have changed since the previous assessment (number of medications, for example). The close follow-up of participants included in the control arms of prevention trials can provide useful information 
about the natural history of frailty. Due to eligibility criteria, participants in prevention trials are initially mostly non-frail, enabling us to observe the occurrence of frailty longitudinally. ${ }^{20}$ In this context, this study aimed to describe changes in frailty status among individuals included in the non-multidomain intervention arms of the Multidomain Alzheimer Preventive Trial (MAPT) during the first 3 years of their participation, and the factors associated with the different transitions.

\section{Material and methods}

\section{Study design and population}

The MAPT study is a phase III, multicenter $(\mathrm{n}=13)$, randomized, placebo-controlled trial, using a four-arm design with three treatment groups (omega-3 alone, multidomain intervention alone, and omega-3 plus multidomain intervention) and a placebo group. ${ }^{21}$ The MAPT study was designed to assess the efficacy of isolated supplementation with omega-3 fatty acid, an isolated multidomain intervention (consisting of nutritional counseling, physical exercise, and cognitive stimulation) or a combination of the two interventions on changes in cognitive function in community-dwelling individuals aged 70 years and older for a period of 3 years. Participants were recruited between May 2008 and February 2011 from community-dwelling elderly people aged 70 years or older who met at least one of three criteria:

- Spontaneous memory complaint expressed to the general practitioner;

- Limitation in one instrumental activity of daily living (IADL, i.e., ability to use the telephone, shop, prepare meals, do housekeeping, do one's laundry, use transportation, follow a medication schedule, or manage money); 
- Slow walking speed (lower than $0.8 \mathrm{~m} / \mathrm{s}$, i.e. more than 5 seconds required to walk 4 meters).

Subjects with dementia were excluded as well as subjects with a Mini Mental State Examination (MMSE) score lower than 24, subjects assessed as dependent for any of the basic activities of daily living (an ADL score lower than 6 [range: 0-6]), and subjects with any disease that could compromise their participation. In addition, subjects who had taken omega-3 supplements within the past 6 months were not included.

The MAPT study included 1680 participants, of whom only those included in the nonmultidomain intervention arms were considered in the present study (420 in the control arm and 423 in the omega-3 arm). As mentioned above, the use of the control arm was intended to enable observation of the natural history of frailty in the absence of specific interventions. In order to increase the power of the study and because the omega-3 supplementation did not significantly affect frailty status over time in the MAPT study ${ }^{22}$, the subjects included in the omega-3 arm were also considered in the analysis. Although the multidomain intervention did not affect frailty status either, caution prompted us to exclude the individuals who received the multidomain intervention; multidomain interventions are one of the most promising strategies for modifying the course of frailty among older adults ${ }^{23}$ and the MAPT study was not designed to assess the efficacy of the multidomain intervention on frailty. One subject withdrew from the omega-3 arm, resulting in a final sample of 842 .

\section{Data collection}

Follow-up visits were scheduled every 6 months up to 36 months. Assessment of frailty and other variables was conducted at baseline, 6 months and annually at 1,2 and 3 years by research staff blinded to the intervention. 


\section{Frailty}

Frailty phenotype was determined according to the following five criteria, adapted from Fried et $\mathrm{al}^{3}$ :

- Unintentional weight loss $>4.5 \mathrm{~kg}$ in the past year;

- Fatigue, measured by 2 questions from the CES-D depression scale;

- Low grip strength, based on the best of 3 measurements with preferred hand;

- Slow walking speed, based on the best of two measurements over 4 meters;

- Low level of physical activity, expressed in weekly energy expenditure relating to time spent doing leisure and physical activities. ${ }^{24}$

Further details about the assessment of frailty (exact formulation of the questions and coding) are given in Appendix 1.

Frail subjects were those meeting three or more of the five criteria. Those meeting one or two of the five criteria were considered pre-frail. The frailty phenotype could only be determined if information about all 5 criteria was available (no imputation of missing data).

\section{Other variables}

Baseline information included age, gender, and treatment arm, as well as the following variables that were also collected at each follow-up:

- $\quad$ Body Mass Index (BMI);

- $\quad$ Polypharmacy defined as $\geq 6$ drugs, $;^{25}$

- Health disorders using the MedDRA System Organ Class classification (considering diseases up to 12 months before baseline);

- Probable depression, measured by a Geriatric Depression Scale 15-item version (GDS-

15) score of $>5 ;^{26}$ 
- Cognitive impairment, measured by a Mini-Mental State Examination (MMSE) score of $\leq 26 ;^{27}$

- Physical function as measured by the Alzheimer's Disease Cooperative Study-Activities of Daily Living Prevention Instrument (ADCS-ADL PI), ${ }^{28}$ dichotomized according to the median value in the study sample;

- Biochemical abnormalities (whether clinically significant or not) reported by investigators in the case report form. Based on individual test results (not available for the present study), the investigators rated for each parameter whether the result was normal or not and, if not, whether a clinical effect could be related to the biochemical abnormality.

All variables except gender were updated at each follow-up.

\section{Statistics}

The characteristics of the participants were described for the study sample and by frailty group in terms of proportions for categorical variables and means +/- standard deviation for continuous variables. Comparison between groups used Chi-square test or Fisher's exact test for categorical variables and analysis of variance for continuous variables.

As recommended for panel data where individuals are observed at arbitrary continuous times, here periodical medical visits, we used multistate modelling to describe how individuals moved between frailty states during the follow-up (states were unknown between observation times). Intensity of transition (i.e. instantaneous risk of moving from one state to another) may depend on time $\mathrm{t}$ (but we assume here time-homogenous intensities) or, more generally, on a set of individual-level or time-dependent explanatory variables. Factors associated with the 4 main transitions (from non-frail to pre-frail, from pre-frail to frail, from frail to pre-frail, and from 
pre-frail to non-frail) were assessed by introducing covariates in the multistate model. The model was specified so that covariates applied to all intensities. Time-dependent covariates were assumed to be constant between the times they were observed, and the transition probability between a pair of times $\left(t_{1} ; t_{2}\right)$ is assumed to depend on the covariate value at $t_{1}$. Variables significantly associated with at least one transition in bivariate analysis were introduced in the final model (namely gender, age, ADCS-ADL score, BMI category, polypharmacy, number of health disorders, probable depression, and abnormal CRP). More details about the model are given in Appendix 2. Results are given in terms of transition intensities with adjusted Hazard Ratios (HR) and 95\% Confidence Intervals (CI) for each covariate. Analyses were performed using Stata ${ }^{\circledR}$ v13 and R (MSM package). ${ }^{29}$

\section{Results}

\section{Characteristics of the study sample at baseline}

The study sample was composed of $65.1 \%$ women and mean age was $75.4+/-4.5$. Memory complaint was the main reason for inclusion $(n=836$; 99.3\%), far ahead of IADL limitations $(54 ; 6.4 \%)$ and slow walking speed $68 ; 8.1 \%)$. We were able to determine the frailty phenotype of 807 individuals at baseline (95.8\%). Of these, $430(53.3 \%)$ were non-frail, $349(43.2 \%)$ prefrail, and $28(3.5 \%)$ frail. Fatigue, low grip strength and low level of physical activity were the factors that contributed most to frailty. The characteristics of the study sample by frailty status are described further in Table 1. 
Table 1. Characteristics of the study sample at baseline by frailty status

\begin{tabular}{llllll}
\hline Total & Non-frail & Pre-frail & Frail & $p^{*}$ \\
& $\mathbf{N}=807$ & $\mathbf{N}=430$ & $\mathbf{N}=\mathbf{3 4 9}$ & $\mathbf{N}=\mathbf{2 8}$ & \\
\hline
\end{tabular}

General information

Arm of the MAPT trial

$\begin{array}{llllll}\text { Placebo } & 401(49.7) & 224(52.1) & 166(47.6) & 11(39.3) & 0.242 \\ \text { Omega 3 } & 406(50.3) & 206(47.9) & 183(52.4) & 17(60.7)\end{array}$

Gender

0.177

Male

$285(33.3) \quad 141(49.5) \quad 131(37.5) \quad 13(4.6)$

Female

$522(64.7) \quad 289(67.2) \quad 218(62.5) \quad 15(53.6)$

Age

$\begin{array}{lllll}70-74 \text { years } & 396(49.1) & 249(57.9) & 137(39.3) & 10(35.7) \\ 75-79 \text { years } & 262(32.5) & 134(31.2) & 120(34.4) & 8(28.6) \\ 80 \text { years and over } & 149(18.5) & 47(10.9) & 92(26.4) & 10(35.7)\end{array}$

ADCS score at baseline

$428(53.3) \quad 259(60.7) \quad 163(46.8) \quad 6(21.4)$

41-45 (less disabled)

$375(46.7) \quad 168(39.3) \quad 185(53.2) \quad 22(78.6)$

BMI $\left(\mathrm{kg} / \mathrm{m}^{2}\right)$

$$
\begin{aligned}
& 16-24 \mathrm{~kg} / \mathrm{m}^{2} \\
& 25-29 \mathrm{~kg} / \mathrm{m}^{2} \\
& 30 \mathrm{~kg} / \mathrm{m}^{2} \text { and over }
\end{aligned}
$$

$336(41.8) \quad 208(48.6) \quad 122(36.2) \quad 6(21.4)$

$336(41.8) \quad 173(40.4) \quad 147(42.4) \quad 16(57.1)$

$131(16.3)$

$47(11.0)$

$78(22.5)$

$6(21.4)$

Health information

Polypharmacy ( $\geq 6$ drugs)

Cognitive impairment

Probable depression

Number of health disorders, mean+/-SD

\section{Biochemical abnormalities}

Total cholesterol

$\begin{array}{lllll}284(35.2) & 128(29.8) & 148(42.4) & 8(28.6) & 0.001 \\ 132(16.4) & 61(14.2) & 61(17.5) & 10(35.7) & 0.009 \\ 142(17.7) & 48(11.2) & 83(24.0) & 11(39.3) & <0.001 \\ 4.8+/-2.6 & 4.4+/-2.5 & 5.3+/-2.6 & 5.1+/-2.5 & <0.001 \\ & & & & \\ 347(43.9) & 185(43.7) & 148(43.7) & 14(50.0) & 0.804\end{array}$




\begin{tabular}{llllll}
\hline & Total & Non-frail & Pre-frail & Frail & $\mathbf{p}^{*}$ \\
& $\mathbf{N}=\mathbf{8 0 7}$ & $\mathbf{N = 4 3 0}$ & $\mathbf{N = 3 4 9}$ & $\mathbf{N = 2 8}$ & \\
\hline Triglycerides & $295(37.2)$ & $145(34.2)$ & $133(39.0)$ & $17(60.7)$ & 0.013 \\
Creatinine & $119(15.2)$ & $51(12.3)$ & $59(17.3)$ & $9(32.1)$ & 0.006 \\
CRP & $86(11.9)$ & $39(9.9)$ & $41(13.4)$ & $6(25.0)$ & 0.045 \\
Hemoglobin & $50(6.3)$ & $19(4.4)$ & $27(7.9)$ & $4(14.3)$ & 0.025 \\
Frailty criteria & & & & & \\
Unintentional weight loss & $39(4.8)$ & 0 & $32(9.2)$ & $7(25.0)$ & - \\
Fatigue & $135(16.7)$ & 0 & $110(31.5)$ & $25(89.3)$ & - \\
Low grip strength & $194(24.0)$ & 0 & $171(49.0)$ & $23(82.1)$ & - \\
Slow walking speed & $22(2.7)$ & 0 & $13(3.7)$ & $9(32.1)$ & - \\
Low level of physical activity & $124(15.4)$ & 0 & $101(28.9)$ & $23(82.1)$ & - \\
\hline
\end{tabular}

Figures are $n(\%)$, except for the number of diseases.

* Chi2 test or Fisher's exact test for categorical variables and analysis of variance for continuous variables Abbreviations: $M A P T=$ Multidomain Alzheimer Preventive Trial, ADCS=Alzheimer's Disease Cooperative StudyActivities of Daily Living Prevention Instrument, BMI=Body Mass Index, CRP=C-Reactive Protein 


\section{Follow-up of frailty}

We were able to determine the frailty phenotype of 711 individuals at 6 months (86.8\%), 626 at 12 months (83.0\%), 550 at 24 months (81.7\%), and 562 at 36 months (84.6\%). The proportion of non-frail individuals decreased during the follow-up (Figure 1). We recorded 18 deaths during the follow-up.

Figure 1. Evolution of the proportion of individuals in each frailty state during the followup

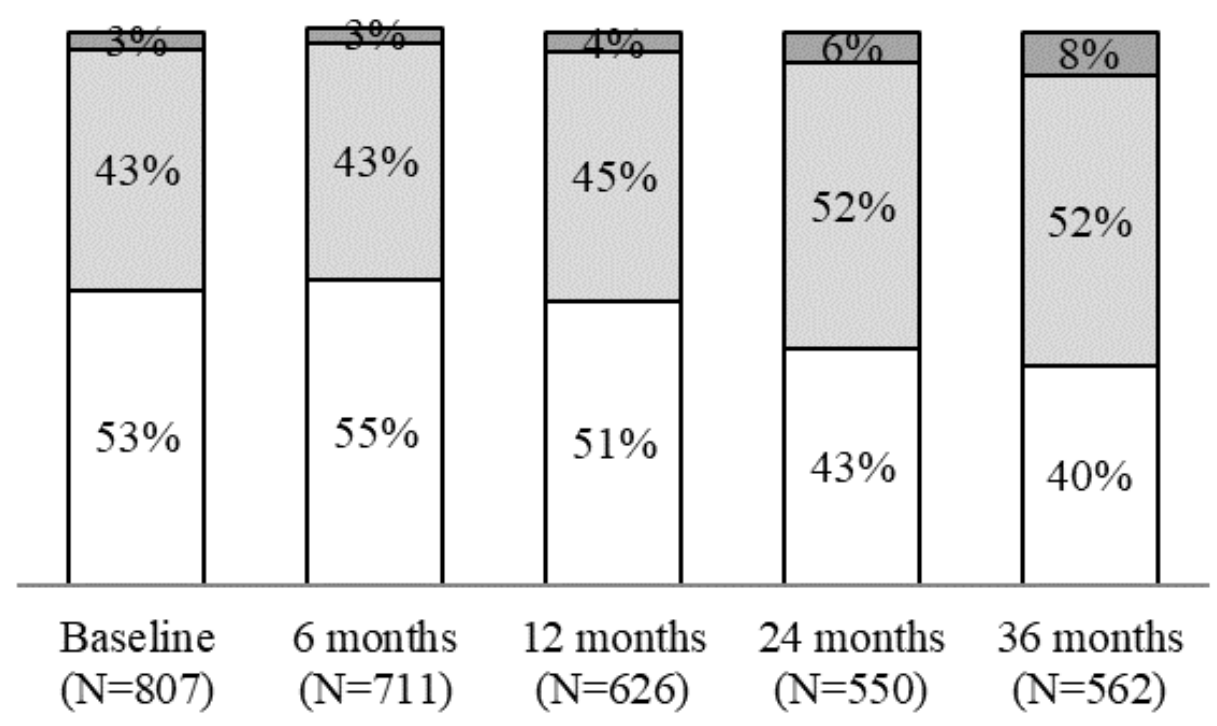

\section{口Non-frail aPre-frail 口Frail}

A total of 2271 pairs of consecutive measurements of frailty status were available over the 3 years of follow-up, with no change in frailty status in 1548 of them (68\%), a worsening of frailty status in 426 of them (19\%), and an improvement in frailty status in the remaining 297 $(13 \%)$. The transition matrix (Table 2) shows that non-frail and pre-frail people often remained in the same state from one assessment to another; $70.8 \%$ of non-frail people remained non-frail 
and $67.4 \%$ of pre-frail people remained pre-frail. Worsening transitions represented $29.1 \%$ of consecutive measurements from the non-frail state and $8.2 \%$ from the pre-frail state. Transitions in the direction of recovery amounted to $24.4 \%$ of consecutive measurements from the pre-frail state and to $64.8 \%$ of those from the frail state. Of note, direct transitions from non-frail to frail or from frail to non-frail were very rare.

Table 2. Transition matrix

\begin{tabular}{ll|cccc}
\hline & & To & & \multicolumn{1}{c}{ Total } \\
& & Non-frail & Pre-frail & Frail & \\
\hline From & Non-frail & $831(70.8)$ & $335(28.6)$ & $7(0.6)$ & $1173(100.0)$ \\
& Prefrail & $251(24.4)$ & $692(67.4)$ & $84(8.2)$ & $1027(100.0)$ \\
& Frail & $5(7.0)$ & $41(57.8)$ & $25(35.2)$ & $71(100.0)$ \\
\hline
\end{tabular}

Figures are $n(\%)$.

Note: Transitions are defined between 2 consecutive assessments of frailty.

\section{Factors influencing transitions}

Results of the multistate model are presented in Table 3. We did not identify factors associated with the transition from pre-frail to frail states. The only factors associated with the transition from non-frail to pre-frail state were polypharmacy and probable depression. Female gender was systematically associated with a lower probability of recovering from pre-frailty and frailty. Older age, overweight, comorbidity, and abnormal CRP also reduced the probability of recovering from frailty or pre-frailty. Of note, the arm in the MAPT trial (control or omega-3) was not included in the final model because it did not influence the likelihood of the transitions in bivariate analysis. 
Table 3. Multistate model assessing factors influencing transitions between frailty states

\begin{tabular}{|c|c|c|c|c|}
\hline \multirow[t]{4}{*}{ Variables } & \multicolumn{4}{|c|}{ Transitions between frailty states } \\
\hline & From non-frail to & From pre-frail to & From pre-frail to & From frail to pre- \\
\hline & pre-frail & non-frail & frail & frail \\
\hline & $\mathbf{N}=335$ & $\mathrm{~N}=\mathbf{2 5 1}$ & $\mathrm{N}=84$ & $\mathrm{~N}=41$ \\
\hline \multicolumn{5}{|l|}{ Gender } \\
\hline Male & 1 & 1 & 1 & 1 \\
\hline Female & $1.12(0.82-1.53)$ & $0.70(0.49-0.98)$ & $0.69(0.30-1.58)$ & $0.32(0.12-0.84)$ \\
\hline \multicolumn{5}{|l|}{ Age } \\
\hline 70-74 years & 1 & 1 & 1 & 1 \\
\hline $75-79$ years & $1.05(0.78-1.41)$ & $0.57(0.40-0.81)$ & $0.94(0.37-2.38)$ & $0.36(0.11-1.12)$ \\
\hline 80 years and over & $1.45(0.98-2.16)$ & $0.43(0.27-0.68)$ & $1.27(0.47-3.44)$ & $0.39(0.12-1.31)$ \\
\hline ADCS score <41 & $1.13(0.84-1.52)$ & $0.93(0.66-1.29)$ & $1.79(0.84-3.85)$ & $1.50(0.55-4.08)$ \\
\hline \multicolumn{5}{|l|}{ BMI } \\
\hline $16-24 \mathrm{~kg} / \mathrm{m}^{2}$ & 1 & 1 & 1 & 1 \\
\hline $25-29 \mathrm{~kg} / \mathrm{m}^{2}$ & $1.09(0.81-1.46)$ & $0.64(0.45-0.90)$ & $0.52(0.21-1.30)$ & $0.52(0.15-1.77)$ \\
\hline $30 \mathrm{~kg} / \mathrm{m}^{2}$ and over & $1.26(0.84-1.91)$ & $0.64(0.40-1.02)$ & $1.79(0.58-5.54)$ & $1.28(0.28-5.94)$ \\
\hline Polypharmacy ( $\geq 6$ drugs) & 1.44 (1.07-1.96) & $1.19(0.83-1.69)$ & $0.98(0.44-2.20)$ & $0.85(0.29-2.46)$ \\
\hline Number of health disorders & $1.02(0.97-1.08)$ & $0.98(0.92-1.05)$ & $0.92(0.78-1.07)$ & $0.75(0.61-0.93)$ \\
\hline \multicolumn{5}{|l|}{$(+1)^{*}$} \\
\hline Probable depression & $1.49(1.01-2.18)$ & $0.72(0.48-1.10)$ & $1.92(0.81-4.55)$ & $0.86(0.26-2.18)$ \\
\hline Abnormal CRP & $1.16(0.79-1.70)$ & $0.58(0.35-0.97)$ & $1.20(0.51-2.81)$ & $1.05(0.37-2.98)$ \\
\hline
\end{tabular}

Values are adjusted hazard ratios $+95 \%$ CI

Abbreviations: ADCS=Alzheimer's disease cooperative Study-Activities of Daily Living Prevention Instrument, BMI=Body Mass Index, GDS=Geriatric Depression Scale, CRP=C-Reactive Protein

* Hazard ratios for each additional health disorder; for instance each additional health disorder reduced the probability of recovery from frailty to pre-frailty of $25 \%$. 


\section{Discussion}

\section{Transitions between frailty states}

Nested in a prevention trial among older adults reporting memory or physical complaints, this study enabled us to describe transitions between frailty states over relatively short time intervals. We confirm that transitions occur most commonly between adjacent frailty states, ${ }^{10}$ $13,16,17,30$ reinforcing the hypothesis of a progressive evolution across the frailty continuum. Our results are also in line with previous findings showing that chances of recovery from frailty are usually equal or superior to chances of recovery from pre-frailty in longitudinal settings, ${ }^{10}$, 13, 16, 17 probably because of a selection effect where the most frail are more likely to be lost to follow-up. ${ }^{31}$

\section{Factors associated with the transitions}

The analysis of the factors associated with the transitions showed that incident pre-frailty was associated with polypharmacy, defined as $\geq 6$ drugs according to the recommended threshold for studies in the area of frailty. ${ }^{25}$ The potential contribution of medications to frailty has been suggested previously ${ }^{32}$, often based on cross-sectional associations. ${ }^{33,34}$ Our results supplement those of Wang et al and Saum et al who demonstrated that polypharmacy increased the risk of incident phenotypic frailty in longitudinal settings. ${ }^{35,36}$ Although contradictory results exist ${ }^{14}$ and residual confounding bias by comorbidity cannot be excluded, this association seems plausible. Indeed, polypharmacy may increase the risk of receiving inappropriate prescriptions and of experiencing adverse drug events that can, in turn, cause or precipitate frailty. ${ }^{37}$ Probable depression, assessed using the GDS-15, was also associated with incident pre-frailty, consistent with previous results from a US cohort that reported that depressive symptoms and 
antidepressant use increased the risk of incident frailty among women aged 65 and older and not frail at baseline. ${ }^{38}$

Other factors identified in the transition analysis were negatively associated with recovery. Among them, female sex and higher age were negatively associated with improvement in frailty status. The former association brings new elements to the "male-female health-survival paradox", 39 i.e. the fact that women live longer despite bearing a larger burden of health deficits than men. The latter association has been previously shown in Chinese and Italian cohorts. ${ }^{13,17}$ The same pattern was found regarding improvement of cognitive/physical function in older adults included in the New Mexico Aging Process Study. ${ }^{40}$ Comorbidity also diminished the chances of recovery from frailty. Consistent with the strong overlap between frailty and comorbidity, diversity of health disorders was found to be associated with frailty transitions in the literature, notably respiratory, cardiovascular, metabolic, malignant diseases, osteoarthritis and stroke. ${ }^{13,16,17}$

The role of overweight and obesity in frailty transitions is controversial. In an Italian cohort of older adults, overweight and obesity raised the risk of pre-frailty among non-frail individuals whereas pre-frail individuals seemed to benefit from being overweight. ${ }^{17}$ Here, the results indicated the deleterious effect of overweight, with lower odds of recovery from a pre-frail state in overweight individuals compared with those not overweight.

Cross-sectional associations between frailty and increased levels of inflammatory mediators, especially IL-6 and its surrogate CRP, have been reported..$^{41}$ In a sample of $>5000$ older men in the United States, Pollack et al found that men with high levels of inflammatory markers were more likely to progress in frailty (CRP in highest quartile) and less likely to improve (IL-6 in the highest quartile). ${ }^{16}$ We confirmed the latter finding by showing that abnormal levels of CRP were negatively associated with recovery from pre-frailty to non-frail status. 


\section{Strength and limitations}

The main strength of this study is the repeated assessment of the frailty phenotype over 3 years, with objective measurements of grip strength and walking speed. Intervals of 6 to 12 months between visits reduced the possibility of missed transitions over short intervals. Limitations included the low number of frail subjects at baseline. The prevalence of frailty was $3.5 \%$ whereas it is expected to be about $15 \%$ in a population of mean age 75 years. ${ }^{34}$ This low prevalence may be explained by the fact that this study was conducted as part of randomized controlled trial whose population may not be representative of the elderly population. ${ }^{42}$ The low number of frail individuals at baseline $(\mathrm{n}=28)$ limited the power of this study to detect factors associated with worsening or improving frailty and made stratified analyses by age or gender impossible. Furthermore, this selection bias may have been aggravated by the fact that pre-frail and frail individuals were more likely to be lost to follow-up compared to non-frail ones, the proportions of individuals lost to follow-up at 36 months being $23 \%, 28 \%$ and $36 \%$ in non-frail, pre-frail and frail individuals at baseline respectively. As a consequence of the low number of frail individuals at baseline and of the attrition of the study sample, the generalizability of our results remains limited. Lastly, we did not have thorough information about biochemical parameters, except doctor-diagnosed abnormalities, nor could we take into account social factors.

\section{Conclusion}

In a sample of older adults participating in a 3-year prevention trial, this study showed that polypharmacy and depressive mood increased the risk of incident pre-frailty. On the other hand, 
we identified factors associated with poorer odds of recovery among frail or pre-frail individuals. They were: female gender, older age, multiple health problems, overweight and elevated CRP. The findings of this study should be confirmed in larger settings to guide policies directed at preventing or managing frailty.

\section{Statements}

\section{Ethics}

The study protocol was approved by the French Ethics Committee located in Toulouse (CPP SOOM II) on December 6, 2007 and authorized by French health authority (Ministry of Health) on December 31, 2007. Written consent was obtained from all participants. The protocol is registered on a public-access clinical trial database (www.clinicaltrials.gov) [NCT00672685)].

\section{Funding}

The MAPT study was supported by grants from the Gérontopôle of Toulouse, the French Ministry of Health (PHRC 2008, 2009), Pierre Fabre Research Institute (manufacturer of the omega-3 supplement), Exhonit Therapeutics SA, and Avid Radiopharmaceuticals Inc. The promotion of this study was supported by the University Hospital Center of Toulouse. The data sharing activity was supported by the Association Monegasque pour la Recherche sur la maladie d'Alzheimer (AMPA) and the UMR 1027 Unit INSERM-University of Toulouse III.

\section{Competing interests}

The authors have no conflicts of interest to declare.

\section{Authors' contribution}


All the authors meet the ICMJE criteria for authorship:

- Substantial contributions to the conception or design of the work; or the acquisition, analysis, or interpretation of data for the work; AND

- Drafting the work or revising it critically for important intellectual content; AND

- Final approval of the version to be published; AND

- Agreement to be accountable for all aspects of the work in ensuring that questions related to the accuracy or integrity of any part of the work are appropriately investigated and resolved.

\section{Acknowledgments}

We are grateful to Grégory Guernec for his statistical counseling.

*MAPT study group:

Principal investigator: Bruno Vellas (Toulouse); Coordination: Sophie Guyonnet; Project leader: Isabelle Carrié; CRA: Lauréane Brigitte; Investigators: Catherine Faisant, Françoise Lala, Julien Delrieu, Hélène Villars;; Psychologists: Emeline Combrouze, Carole Badufle, Audrey Zueras; Methodology, statistical analysis and data management: Sandrine Andrieu, Christelle Cantet, Christophe Morin; Multidomain group: Gabor Abellan Van Kan, Charlotte Dupuy, Yves Rolland (physical and nutritional components), Céline Caillaud, Pierre-Jean Ousset (cognitive component), Françoise Lala (preventive consultation), Bertrand Fougère (Toulouse). The cognitive component was designed in collaboration with Sherry Willis from the University of Seattle, and Sylvie Belleville, Brigitte Gilbert and Francine Fontaine from the University of Montreal.

Co-Investigators at associated centres: Jean-François Dartigues, Isabelle Marcet, Fleur Delva, Alexandra Foubert, Sandrine Cerda (Bordeaux); Marie-Noëlle-Cuffi, Corinne Costes (Castres); 
Olivier Rouaud, Patrick Manckoundia, Valérie Quipourt, Sophie Marilier, Evelyne Franon (Dijon); Lawrence Bories, Marie-Laure Pader, Marie-France Basset, Bruno Lapoujade, Valérie Faure, Michael Li Yung Tong, Christine Malick-Loiseau, Evelyne Cazaban-Campistron (Foix); Françoise Desclaux, Colette Blatge (Lavaur); Thierry Dantoine, Cécile Laubarie-Mouret, Isabelle Saulnier, Jean-Pierre Clément, Marie-Agnès Picat, Laurence Bernard-Bourzeix, Stéphanie Willebois, Iléana Désormais, Noëlle Cardinaud (Limoges); Marc Bonnefoy, Pierre Livet, Pascale Rebaudet, Claire Gédéon, Catherine Burdet, Flavien Terracol (Lyon), Alain Pesce, Stéphanie Roth, Sylvie Chaillou, Sandrine Louchart (Monaco); Kristelle Sudres, Nicolas Lebrun, Nadège Barro-Belaygues (Montauban); Jacques Touchon, Karim Bennys, Audrey Gabelle, Aurélia Romano, Lynda Touati, Cécilia Marelli, Cécile Pays (Montpellier); Philippe Robert, Franck Le Duff, Claire Gervais, Sébastien Gonfrier (Nice); Yannick Gasnier and Serge Bordes, Danièle Begorre, Christian Carpuat, Khaled Khales, Jean-François Lefebvre, Samira Misbah El Idrissi, Pierre Skolil, Jean-Pierre Salles (Tarbes).

MRI group: Carole Dufouil (Bordeaux), Stéphane Lehéricy, Marie Chupin, Jean-François Mangin, Ali Bouhayia (Paris); Michèle Allard (Bordeaux); Frédéric Ricolfi (Dijon); Dominique Dubois (Foix); Marie Paule Bonceour Martel (Limoges); François Cotton (Lyon); Alain Bonafé (Montpellier); Stéphane Chanalet (Nice); Françoise Hugon (Tarbes); Fabrice Bonneville, Christophe Cognard, François Chollet (Toulouse).

PET scans group: Pierre Payoux, Thierry Voisin, Julien Delrieu, Sophie Peiffer, Anne Hitzel, (Toulouse); Michèle Allard (Bordeaux); Michel Zanca (Montpellier); Jacques Monteil (Limoges); Jacques Darcourt (Nice).

Medico-economics group: Laurent Molinier, Hélène Derumeaux, Nadège Costa (Toulouse). Biological sample collection: Christian Vincent, Bertrand Perret, Claire Vinel (Toulouse). Safety management: Pascale Olivier-Abbal 
DSA Group:

Sandrine Andrieu, Christelle Cantet, Nicola Coley

\section{References}

1. Clegg A, Young J, Iliffe S, Rikkert MO, Rockwood K. Frailty in elderly people. Lancet. 2013; 381:752-62.doi:10.1016/S0140-6736(12)62167-9

2. Buta BJ, Walston JD, Godino JG, Park M, Kalyani RR, Xue QL, et al. Frailty assessment instruments: Systematic characterization of the uses and contexts of highly-cited instruments. Ageing research reviews. 2016; 26:53-61.doi:10.1016/j.arr.2015.12.003

3. Fried LP, Tangen CM, Walston J, Newman AB, Hirsch C, Gottdiener J, et al. Frailty in older adults: evidence for a phenotype. J Gerontol A Biol Sci Med Sci. 2001; 56:M146-56

4. Shamliyan T, Talley KM, Ramakrishnan R, Kane RL. Association of frailty with survival: a systematic literature review. Ageing research reviews. 2013; 12:71936.doi:10.1016/j.arr.2012.03.001

5. Collard RM, Boter H, Schoevers RA, Oude Voshaar RC. Prevalence of frailty in community-dwelling older persons: a systematic review. J Am Geriatr Soc. 2012; 60:148792.doi:10.1111/j.1532-5415.2012.04054.x

6. Bergman H, Ferrucci L, Guralnik J, Hogan DB, Hummel S, Karunananthan S, et al. Frailty: an emerging research and clinical paradigm--issues and controversies. J Gerontol A Biol Sci Med Sci. 2007; 62:731-7.doi:62/7/731 [pii]

7. Rodriguez-Manas L, Feart C, Mann G, Vina J, Chatterji S, Chodzko-Zajko W, et al. Searching for an operational definition of frailty: a Delphi method based consensus statement: 
the frailty operative definition-consensus conference project. J Gerontol A Biol Sci Med Sci. 2013; 68:62-7.doi:10.1093/gerona/gls119

8. Morley JE, Vellas B, van Kan GA, Anker SD, Bauer JM, Bernabei R, et al. Frailty consensus: a call to action. Journal of the American Medical Directors Association. 2013; 14:392-7.doi:10.1016/j.jamda.2013.03.022

9. Puts MT, Toubasi S, Andrew MK, Ashe MC, Ploeg J, Atkinson E, et al. Interventions to prevent or reduce the level of frailty in community-dwelling older adults: a scoping review of the literature and international policies. Age Ageing. 2017; 46:38392.doi:10.1093/ageing/afw247

10. Gill TM, Gahbauer EA, Allore HG, Han L. Transitions between frailty states among community-living older persons. Archives of internal medicine. 2006; 166:41823.doi:10.1001/archinte.166.4.418

11. Shardell M, D'Adamo C, Alley DE, Miller RR, Hicks GE, Milaneschi Y, et al. Serum 25-hydroxyvitamin $\mathrm{D}$, transitions between frailty states, and mortality in older adults: the Invecchiare in Chianti Study. J Am Geriatr Soc. 2012; 60:256-64.doi:10.1111/j.15325415.2011.03830.x

12. Xue QL, Bandeen-Roche K, Varadhan R, Zhou J, Fried LP. Initial manifestations of frailty criteria and the development of frailty phenotype in the Women's Health and Aging Study II. J Gerontol A Biol Sci Med Sci. 2008; 63:984-90

13. Lee JS, Auyeung TW, Leung J, Kwok T, Woo J. Transitions in frailty states among community-living older adults and their associated factors. Journal of the American Medical Directors Association. 2014; 15:281-6.doi:10.1016/j.jamda.2013.12.002

14. Jamsen KM, Bell JS, Hilmer SN, Kirkpatrick CM, Ilomaki J, Le Couteur D, et al. Effects of Changes in Number of Medications and Drug Burden Index Exposure on Transitions 
Between Frailty States and Death: The Concord Health and Ageing in Men Project Cohort Study. J Am Geriatr Soc. 2016; 64:89-95.doi:10.1111/jgs.13877

15. Arrighi Y, Rapp T, Sirven N. The impact of economic conditions on the disablement process: AMarkov transition approach using SHARE data. Health Policy. 2017; 121:77885.doi:10.1016/j.healthpol.2017.05.002

16. Pollack LR, Litwack-Harrison S, Cawthon PM, Ensrud K, Lane NE, Barrett-Connor E, et al. Patterns and Predictors of Frailty Transitions in Older Men: The Osteoporotic Fractures in Men Study. J Am Geriatr Soc. 2017; 65:2473-9.doi:10.1111/jgs.15003

17. Trevisan C, Veronese N, Maggi S, Baggio G, Toffanello ED, Zambon S, et al. Factors Influencing Transitions Between Frailty States in Elderly Adults: The Progetto Veneto Anziani Longitudinal Study. J Am Geriatr Soc. 2017; 65:179-84.doi:10.1111/jgs.14515

18. Stenholm S, Ferrucci L, Vahtera J, Hoogendijk EO, Huisman M, Pentti J, et al. Natural Course of Frailty Components in People Who Develop Frailty Syndrome: Evidence From Two Cohort Studies. J Gerontol A Biol Sci Med Sci. 2018.doi:10.1093/gerona/gly132

19. Balboa-Castillo T, Struijk EA, Lopez-Garcia E, Banegas JR, Rodriguez-Artalejo F, Guallar-Castillon P. Low vitamin intake is associated with risk of frailty in older adults. Age Ageing. 2018.doi:10.1093/ageing/afy105

20. Dapp U, Minder CE, Anders J, Golgert S, von Renteln-Kruse W. Long-term prediction of changes in health status, frailty, nursing care and mortality in community-dwelling senior citizens-results from the Longitudinal Urban Cohort Ageing Study (LUCAS). BMC Geriatr. 2014; 14:141.doi:10.1186/1471-2318-14-141

21. Vellas B, Carrie I, Gillette-Guyonnet S, Touchon J, Dantoine T, Dartigues JF, et al. Mapt Study: A Multidomain Approach for Preventing Alzheimer's Disease: Design and Baseline Data. The journal of prevention of Alzheimer's disease. 2014; 1:13-22 
22. Andrieu S, Guyonnet S, Coley N, Cantet C, Bonnefoy M, Bordes S, et al. Effect of longterm omega 3 polyunsaturated fatty acid supplementation with or without multidomain intervention on cognitive function in elderly adults with memory complaints (MAPT): a randomised, placebo-controlled trial. Lancet Neurol. 2017; 16:377-89.doi:10.1016/S14744422(17)30040-6

23. Dedeyne L, Deschodt M, Verschueren S, Tournoy J, Gielen E. Effects of multi-domain interventions in (pre)frail elderly on frailty, functional, and cognitive status: a systematic review. Clinical interventions in aging. 2017; 12:873-96.doi:10.2147/CIA.S130794

24. Ainsworth BE, Haskell WL, Leon AS, Jacobs DR, Jr., Montoye HJ, Sallis JF, et al. Compendium of physical activities: classification of energy costs of human physical activities. Medicine and science in sports and exercise. 1993; 25:71-80

25. Moulis F, Moulis G, Balardy L, Gerard S, Sourdet S, Rouge-Bugat ME, et al. Searching for a polypharmacy threshold associated with frailty. Journal of the American Medical Directors Association. 2015; 16:259-61.doi:10.1016/j.jamda.2014.11.016

26. Yesavage JA, Brink TL, Rose TL, Lum O, Huang V, Adey M, et al. Development and validation of a geriatric depression screening scale: a preliminary report. Journal of psychiatric research. 1982; 17:37-49

27. Folstein MF, Folstein SE, McHugh PR. "Mini-mental state". A practical method for grading the cognitive state of patients for the clinician. Journal of psychiatric research. 1975; 12:189-98

28. Galasko D, Bennett DA, Sano M, Marson D, Kaye J, Edland SD, et al. ADCS Prevention Instrument Project: assessment of instrumental activities of daily living for communitydwelling elderly individuals in dementia prevention clinical trials. Alzheimer disease and associated disorders. 2006; 20:S152-69.doi:10.1097/01.wad.0000213873.25053.2b 
29. Jackson CH. Multi-State Models for Panel Data: The msm Package for R. J Stat Softw. $2011 ; 38: 1-28$

30. Lanziotti Azevedo da Silva S, Campos Cavalcanti Maciel A, de Sousa Maximo Pereira L, Domingues Dias JM, Guimaraes de Assis M, Correa Dias R. Transition Patterns of Frailty Syndrome in Comunity-Dwelling Elderly Individuals: A Longitudinal Study. The Journal of frailty \& aging. 2015; 4:50-5.doi:10.14283/jfa.2015.43

31. Stolz E, Mayerl H, Rasky E, Freidl W. Does Sample Attrition Affect the Assessment of Frailty Trajectories Among Older Adults? A Joint Model Approach. Gerontology. 2018:110.doi:10.1159/000489335

32. Gnjidic D, Hilmer SN. Potential contribution of medications to frailty. J Am Geriatr Soc. 2012; 60:401.doi:10.1111/j.1532-5415.2011.03810.x

33. Herr M, Robine JM, Pinot J, Arvieu JJ, Ankri J. Polypharmacy and frailty: prevalence, relationship, and impact on mortality in a French sample of 2350 old people. Pharmacoepidemiology and drug safety. 2015; 24:637-46.doi:10.1002/pds.3772

34. Herr M, Sirven N, Grondin H, Pichetti S, Sermet C. Frailty, polypharmacy, and potentially inappropriate medications in old people: findings in a representative sample of the French population. Eur J Clin Pharmacol. 2017; 73:1165-72.doi:10.1007/s00228-017-2276-5

35. Wang R, Chen L, Fan L, Gao D, Liang Z, He J, et al. Incidence and Effects of Polypharmacy on Clinical Outcome among Patients Aged 80+: A Five-Year Follow-Up Study. PloS one. 2015; 10:e0142123.doi:10.1371/journal.pone.0142123

36. Saum KU, Schottker B, Meid AD, Holleczek B, Haefeli WE, Hauer K, et al. Is Polypharmacy Associated with Frailty in Older People? Results From the ESTHER Cohort Study. J Am Geriatr Soc. 2017; 65:e27-e32.doi:10.1111/jgs.14718 
37. Fried TR, O'Leary J, Towle V, Goldstein MK, Trentalange M, Martin DK. Health outcomes associated with polypharmacy in community-dwelling older adults: a systematic review. J Am Geriatr Soc. 2014; 62:2261-72.doi:10.1111/jgs.13153

38. Lakey SL, LaCroix AZ, Gray SL, Borson S, Williams CD, Calhoun D, et al. Antidepressant use, depressive symptoms, and incident frailty in women aged 65 and older from the Women's Health Initiative Observational Study. J Am Geriatr Soc. 2012; 60:85461.doi:10.1111/j.1532-5415.2012.03940.x

39. Oksuzyan A, Brønnum-Hansen H, Jeune B. Gender gap in health expectancy. Eur J Ageing. 2010; 7:213-8.doi:10.1007/s10433-010-0170-4

40. Qualls C, Waters D, Vellas B, Villareal D, Garry P, Gallini A, et al. Reversible states of physical and/or cognitive dysfunction: A 9-year longitudinal study. Journal of Nutrition Health and Ageing. 2017; 21:271-5.doi:10.1007/s12603-017-0878-3

41. Fulop T, Larbi A, Witkowski JM, McElhaney J, Loeb M, Mitnitski A, et al. Aging, frailty and age-related diseases. Biogerontology. 2010; 11:547-63.doi:10.1007/s10522-010$9287-2$

42. van Deudekom F, Psotmus I, van der Ham D, Pothof A, Broekhuizen K, Blauw G, et al. External validity of randomized controlled trials in older adults, a systematic review. PloS one. 2017; 12:e0174053.doi:10.1371/journal.pone.0174053 


\section{Supplementary material}

\section{Appendix 1. Details of frailty assessment}

\begin{tabular}{|c|c|c|}
\hline $\begin{array}{l}\text { Frailty } \\
\text { criterion }\end{array}$ & Measurement & $\begin{array}{l}\text { Response or cut-off } \\
\text { corresponding to frailty for } \\
\text { the criterion }\end{array}$ \\
\hline Weight loss & $\begin{array}{l}\text { "In the last year, have you lost more than } 4.5 \mathrm{Kg} \\
\text { unintentionally (i.e., not due to dieting or exercise)?" }\end{array}$ & "Yes" \\
\hline Fatigue & $\begin{array}{l}\text { Exhaustion: Using the CES-D Depression Scale, the } \\
\text { following two statements are read. (a) I felt that } \\
\text { everything I did was an effort; (b) I could not get going. } \\
\text { The } \\
\text { question is asked "How often in the last week did you } \\
\text { feel this way?" } 0 \text { = rarely or none of the time (=1 day), } 1 \\
=\text { some or a little of the time ( } 1-2 \text { days), } 2=\text { a } \\
\text { moderate amount of the time ( } 3-4 \text { days), or } 3=\text { most of } \\
\text { the time. }\end{array}$ & $\begin{array}{l}\text { Answer " } 2 \text { " or " } 3 \text { " to either of } \\
\text { these questions }\end{array}$ \\
\hline Weakness & $\begin{array}{l}\text { Grip strength based on the best of } 3 \text { measurements with } \\
\text { preferred hand, results stratified by gender and body mass } \\
\text { index (BMI) }\end{array}$ & $\begin{array}{l}\text { Men: } \\
\mathrm{BMI} \leq 24 \mathrm{Kg} / \mathrm{m}^{2}: \leq 29 \mathrm{Kg} \\
24.1 \leq \mathrm{BMI} \leq 28 \mathrm{Kg} / \mathrm{m}^{2}: \leq 30 \\
\mathrm{Kg} \\
\mathrm{BMI}>28 \mathrm{Kg} / \mathrm{m}^{2}: \leq 32 \mathrm{Kg} \\
\text { Women: } \\
\mathrm{BMI} \leq 23 \mathrm{Kg} / \mathrm{m}^{2}: \leq 17 \mathrm{Kg} \\
23.1 \leq \mathrm{BMI} \leq 26 \mathrm{Kg} / \mathrm{m}^{2}: \leq 17.3 \\
\mathrm{Kg} \\
26.1 \leq \mathrm{BMI} \leq 29 \mathrm{Kg} / \mathrm{m}^{2}: \leq 18 \\
\mathrm{Kg} \\
\mathrm{BMI}>29 \mathrm{Kg} / \mathrm{m}^{2}: \leq 21 \mathrm{Kg}\end{array}$ \\
\hline Walking speed & $\begin{array}{l}\text { Walking speed based on the best of } 2 \text { measurements over } \\
4 \text { meters, results stratified on gender and height }\end{array}$ & $\begin{array}{l}\text { Men: } \\
\text { Height } \leq 173 \mathrm{~cm}: \geq 7 \text { seconds } \\
\text { Height }>173 \mathrm{~cm}: \geq 6 \text { seconds } \\
\text { Women: } \\
\text { Height } \leq 159 \mathrm{~cm}: \geq 7 \text { seconds } \\
\text { Height }>159 \mathrm{~cm}: \geq 6 \text { seconds }\end{array}$ \\
\hline $\begin{array}{l}\text { Physical } \\
\text { activity }\end{array}$ & $\begin{array}{l}\text { Questionnaire about the time spent doing } 15 \text { activities } \\
\text { during the previous } 2 \text { weeks: walking, chores (moderately } \\
\text { strenuous), mowing the lawn, raking, gardening, hiking, } \\
\text { jogging, biking, exercise cycling, dancing, aerobics, } \\
\text { bowling, golf, gymnastic, and swimming. Kcals per week } \\
\text { expended are calculated using standardized coefficients } \\
\text { per activity (Ainsworth BE, Haskell WL, Leon AS, Jacobs } \\
\text { DR, Jr., Montoye HJ, Sallis JF, et al. Compendium of } \\
\text { physical activities: classification of energy costs of } \\
\text { human physical activities. Medicine and science in sports } \\
\text { and exercise. 1993;25(1):71-80). }\end{array}$ & $\begin{array}{l}\text { Men: }<383 \text { Kcal per week } \\
\text { Women: }<270 \text { Kcal per week }\end{array}$ \\
\hline
\end{tabular}




\section{Appendix 2. Details about the multi-state model}

By supposing $\{\mathrm{X}(\mathrm{t}) ; \mathrm{t} \geq 0\}$ a stochastic process which can take 3 possible states (1: for "nonfrail" state; 2: for "pre-frailty" state and 3: for "frailty" state), we defined the associated transition intensities, $\alpha_{\mathrm{ij}}(\mathrm{t})$ (with $\mathrm{i}$ and $\mathrm{j}$ vary between 1 and 3 ), as the following hazard function:

$\alpha_{i j}(t, Z(t))=\lim _{\Delta t \rightarrow 0} \frac{P(X(t+\Delta t)=11 X(t)=j, Z(t))}{\Delta t}$

Where $\mathrm{Z}(\mathrm{t})$ is the vector of covariates considered, and $\alpha_{\mathrm{ij}}$, the coefficient of interest, included in a $3 * 3$ transition matrix verifying:

$\alpha_{i \mathrm{i}}=-\sum_{\mathrm{j}=\mathrm{i}} \alpha_{\mathrm{ij}}$

In this study, $\alpha_{\mathrm{ij}}(\mathrm{t})$ is estimated by a cox model which could be written as following:

$\alpha_{i j}(t, Z(t))=\alpha_{0 i j}(t) \exp \left(Z(t)^{t} \beta_{i j}\right)$

Where $\alpha_{0 \mathrm{ij}}$ corresponded to the baseline non parametric hazard function and $\beta$ the vector of unknown parameters linked to covariates. 